\title{
Dietary Planning as a Mediator of the Intention-Behavior Relation: An Experimental-Causal-Chain Design
}

\author{
Tabea Reuter,* Jochen P. Ziegelmann, \\ Amelie U. Wiedemann and Sonia Lippke \\ Freie Universitaet Berlin, Germany
}

\begin{abstract}
Health behavior change is seen as a self-regulatory process that consists of a motivation phase of goal setting and a volition phase of goal pursuit. Previous studies suggest that the intention-behavior association is mediated by planning. However, evidence is based on observational studies rather than on experimental designs. To validate the causal assumptions, an experimental-causal-chain design was employed. Study $1(n=145)$ examined whether changing dietary intentions by a motivational intervention engenders changes in planning activities 1 month later. Study $2(n=115)$ examined, in a different sample, whether a volitional planning intervention engenders changes in dietary behavior 1 month later. In both studies, repeated measures ANOVAs revealed a significant Time $\times$ Condition interaction. Changes in intention mediated the effects of the motivational intervention on planning activities (Study 1). Changes in planning mediated the effect of a planning intervention on dietary behavior (Study 2). Previous observational findings on planning as a mediator in the intention-behavior association were supported by the two experiments. The findings might help to identify points of intervention in the process underlying health behavior change.
\end{abstract}

Le changement de comportement au plan de la santé est considéré comme un processus d'auto-régulation qui se compose d'une phase de motivation (fixation des buts) et d'une phase de volition (poursuite des buts). Des études précédentes suggèrent que le passage de l'intention au comportement est médiatisé par la planification. Ces résultats sont obtenus par voie d'observations plutôt que par expérimentations. Pour valider les hypothèses de causalité, un modèle de chaîne-causale-expérimentale a été employé. L'étude 1 examine si, en changeant les intentions alimentaires par une intervention motivationnelle,

* Address for correspondence: Tabea Reuter, Health Psychology, Freie Universitaet Berlin, Habelschwerdter Allee 45, 14195 Berlin, Germany. Email: tabea.reuter@fu-berlin.de

The authors would like to thank Prof. Susan Michie for helpful comments on an earlier draft of this manuscript. During the work on her dissertation, the first author was a pre-doctoral fellow of the International Max Planck Research School "The Life Course: Evolutionary and Ontogenetic Dynamics" (LIFE, www.imprs-life.mpg.de). 
on obtient des changements dans la planification des activités un mois après $(n=145)$. L'étude 2 examine, sur un échantillon différent, si la planification d'une intervention engendre des changements $d u$ comportement alimentaire un mois plus tard $(n=115)$. Pour ces deux études, des ANOVA à mesures répétées révèlent une interaction significative entre le temps et la condition étudiée. Les changements de l'intention influencent les effets de l'intervention motivationnelle sur la planification des activités (étude 1). Les changements de la planification influencent les effets de l'intervention de la volition sur le comportement alimentaire (Etude 2). Les résultats obtenus par observation sur la planification comme lien entre l'intention et le comportement sont confirmés par les expérimentations. Les résultats peuvent permettre d'identifier les modalités d'interventions relatives au processus sous-tendant le changement du comportement de santé.

\section{INTRODUCTION}

Prominent theories of goal-directed action (e.g. Theory of Reasoned Action; Fishbein \& Ajzen, 1975; Theory of Planned Behavior; Ajzen, 1991) assume that intention is the most proximal predictor of behavior. Therefore, research has concentrated on identifying factors that determine the formation of strong intentions. However, these studies have been only moderately successful in predicting goal attainment (Sheeran, 2002). Experimental tests of intention-behavior associations in which intention strength was manipulated revealed that a medium-to-large change in intention produced only a small-to-medium change in behavior (Webb \& Sheeran, 2006). This so-called intention-behavior gap reveals that people do not fully act upon their intentions. Several factors may impede the adoption and maintenance of goal-directed behavior, such as distractions (Metcalfe \& Mischel, 1999), forgetting (Orbell, Hodgkins, \& Sheeran, 1997), or conflicting bad habits (Verplanken \& Faes, 1999). Thus, models of behavior change should pay attention to the "black box" that follows intention formation, unravelling the mechanisms that operate between intention and actual behavior.

The contention that the process of goal-oriented action involves at least two different phases, namely a motivation phase of goal setting and a volition phase of goal striving, was introduced by Lewin, Dembo, Festinger, and Sears (1944). This implies that setting a goal (or forming an intention) is only one prerequisite for attaining a goal. In the volition phase, selfregulatory skills and strategies foster the successful translation of intentions into action (Gollwitzer, 1999).

The integration of such volitional factors might help to explicate the causal mechanism by which intentions influence behavior. By trying to explain the mechanism through which the causation occurs, we go beyond simple intention-behavior models. Proposing mediators of the intentionbehavior relation is useful for both refining the theory and identifying potential points of intervention. 


\section{Planning as a Volitional Mediator of the Intention-Behavior Association}

A large body of research regards planning as a powerful self-regulatory strategy for effective goal pursuit. Miller, Galanter, and Pribram's (1960) systematic study on planning was followed by clinical studies on weight loss (e.g. Bandura \& Simon, 1977; Chapman \& Jeffrey, 1978), academic study (e.g. Greiner \& Karoly, 1976), and children's resistance to temptations (e.g. Mischel \& Patterson, 1976). Research on the role of planning in health behavior change began with Leventhal, Singer, and Jones (1965), who suggested that fear appeals may only be effective in producing a health behavior when specific parameters of the situation (when, where) and an action sequence (how) are provided.

More recently, the concept of implementation intentions has been introduced (Gollwitzer, 1999). In the process of if-then planning (i.e. forming an implementation intention), an action sequence is linked to specific parameters of a situation in terms of when, where, and how to perform a behavior. Planning enhances information processing in terms of increased accessibility, recall, detection, and discrimination of critical cues. Once a specified situation is encountered, the intended behavior is elicited almost automatically (see Gollwitzer \& Sheeran, 2006, for a review).

In Schwarzer's $(1992,2008)$ Health Action Process Approach (HAPA), planning is specified as a mediator of the intention-behavior relationship. This implies that individuals who form an intention will be more likely to engage in planning, and those who do plan will be more likely to engage in the desired behavior. There is ambiguous evidence for the mediating role of planning in the intention-behavior association. Whereas some studies find mediating effects (Norman \& Conner, 2005, Study 2; Schwarzer, Schüz, Ziegelmann, Lippke, Luszcynska, \& Scholz, 2007), others do not (Norman \& Conner, 2005, Study 1; White, Terry, \& Hogg, 1994). However, all studies were observational and do not allow inferences for cause-and-effect relationships.

\section{Theoretical and Statistical Mediation Analysis}

Spencer, Zanna, and Fong (2005) criticise the default use of mediation analysis on the basis of regression models as proposed by Baron and Kenny (1986). Spencer et al. (2005) claim that theoretical mediation analysis is often assumed to be equivalent to statistical mediation analysis on the basis of observational data. In an early paper, Judd and Kenny (1981) caution the reader that a mediational analysis is nothing but a correlational analysis. Even if variables are ordered in time, there are other possible explanations of correlations of longitudinal data, such as spuriousness (Link \& Shrout, 1992). Therefore, a series of experiments that demonstrates the proposed 


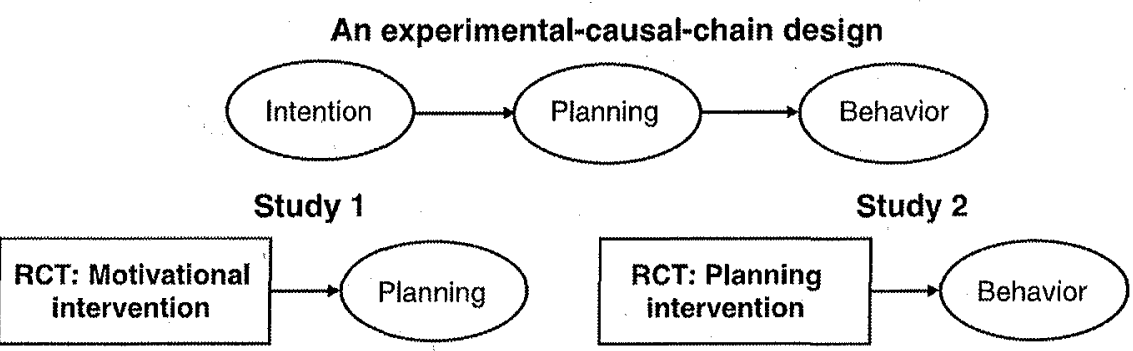

FIGURE 1. Mediation analysis employing an experimental-causal-chain design in which the proposed independent variable (intention) as well as the proposed mediator (planning) is manipulated $(\mathrm{RCT}=$ randomised controlled trial).

causal chain is superior to a statistical mediation analysis. In such "experimental-causal-chain designs" (Spencer et al., 2005), both the independent variable and the mediating variable are manipulated, which allows causal inferences about the chain of events.

\section{Research Aims}

The present research attempts to overcome several limitations of previous studies by providing evidence for a causal chain process of behavior change. We propose that behavioral intentions (independent variable) lead to the intended behavior (dependent variable) through planning (mediating variable). Two studies were conducted to test this proposal. In Study 1, the intention is experimentally manipulated, and in Study 2 planning activities are experimentally manipulated (see Figure 1). By integrating mediating processes, the simple intention-behavior model is refined, and the intervening mechanisms may be identified.

\section{STUDY 1}

Study 1 aims at testing the relation between the independent variable and the mediator. Therefore, the behavioral intention is manipulated experimentally, and self-reported planning is assessed 1 month later.

\section{Method}

Participants and Procedure. Participants were recruited from a large logistics service company. During a routine medical check-up, employees were invited by the physician to participate in a health-promotion program aimed at dietary changes. Persons who were diagnosed with one or more of the following conditions were excluded from the study: manifest diabetes 
mellitus, acute myocardial infarction within last year, contraindication for fruit and/or vegetable consumption. After giving informed consent, participants filled in a questionnaire. Participants $(N=304$, mean age $=44$ years, $S D=$ 8.6 years, $20-64$ years, $84 \%$ men) who reported that they consume less than five portions of fruit and vegetables per day and that they do not intend to change this intake were randomly assigned to a computer-based motivational intervention $(n=263)$ or to a control group $(n=41)$. Questionnaires sent at follow-up were returned by $145(50.5 \%)$ participants. Of those, 122 were in the experimental and 23 in the control group. In terms of self-reported intentions, planning, and dietary behavior, remaining participants at Time 2 did not differ significantly from those who discontinued participation.

Intervention. The intervention was designed to motivate the participants to consume five portions of fruit and vegetables a day. The theoretical framework underlying the motivational intervention was the HAPA (Schwarzer, 1992), which emphasises self-efficacy beliefs, outcome expectancies, and risk perception to change behavioral intentions. The intervention comprised written verbal persuasion for enhancing participants' selfefficacy beliefs to adopt the new behavior, balancing positive and negative consequences (outcome expectancies) of eating fruit and vegetables, as well as risk communication. The control group received basic nutrition information on a computer screen. The intervention and control group treatment was performed using the software dynQuest (Rademacher \& Lippke, 2007).

Measures. Intentions and planning concerning fruit and vegetable consumption were measured at baseline and 4 weeks later. Intentions were assessed with two items such as: "I intend to eat 5 servings of fruit and vegetables a day." Planning was measured with: "I have already precisely planned when, where, and how to eat 5 servings of fruit or vegetables throughout the day." Answers were scored on a 4-point scale (completely disagree, somewhat disagree, somewhat agree, completely agree). All items were adapted from Schwarzer et al. (2007).

Analytical Procedure. Data were analysed using a repeated-measures ANOVA to examine mean differences between the experimental and the control group. Hierarchical regression analyses were employed to test the mediating effects of intention changes in the relation between the experimental versus the control condition and subsequent planning activities. All analyses were conducted with SPSS 13.0.

Missing Values. Missing values $(<5 \%)$ were imputed cross-sectionally using the expectation maximisation algorithm (Enders, 2001). For data missing at random, expectation maximisation estimation has been 
recommended and has proven more robust than regression imputation (Gold \& Bentler, 2000).

\section{Results}

The intervention and control groups did not differ in planning at preintervention, $F(1,302)=2.00$, ns. The first hypothesis concerned the effect of a motivational intervention on planning 1 month later. Means and standard deviations are shown in Table 1. A repeated-measures ANOVA revealed a significant main effect of time, $F(1,141)=5.05, p<.05$ (partial eta $^{2}=.04$ ), as well as a significant Time $\times$ Group interaction, $F(1,141)=5.05, p<.05$ (partial eta ${ }^{2}=.04$, post-hoc observed power test 0.61 ). The results are displayed in Figure 2.

To test whether the differential effects of motivational and control interventions on planning were mediated by change in intention, hierarchical regression models were performed. Time 2 planning was regressed onto baseline planning in the first step in order to predict change in planning. In a second step, the residualised change score of intention was entered as indicator of individual effects of the intervention. This residualised change score was obtained by regressing Time 2 intention onto Time 1 intention, $R^{2}=.25$; $\beta=.50 ; p<.001$. A significant $\beta$ was obtained in the intervention group, $\beta=.60, p<.001$, but not in the control group, $\beta=.38$, ns. The increase in variance explained was statistically significant in the intervention group only, $F(1,115)=34.46, p<.001 ; \Delta R^{2}=.22$; control: $F(1,19)=1.07, \mathrm{~ns} ; \Delta R^{2}=.04$. Thus, intention changes predicted planning changes in the treatment group.

\section{Discussion}

Participants of the motivational treatment significantly increased their planning activities compared to participants of the control group. Moreover, these changes were mediated by changes in intention in the treatment group

TABLE 1

Means and Standard Deviations for Variables in Study 1

\begin{tabular}{|c|c|c|c|c|c|c|c|c|}
\hline & \multicolumn{4}{|c|}{ Motivational Intervention Group } & \multicolumn{4}{|c|}{ Control Group } \\
\hline & \multicolumn{2}{|c|}{ Time 1} & \multicolumn{2}{|c|}{ Time 2} & \multicolumn{2}{|c|}{ Time 1} & \multicolumn{2}{|c|}{ Time 2} \\
\hline & M & SD & M & SD & $\mathbf{M}$ & SD & $\mathbf{M}$ & SD \\
\hline Intention & 1.73 & 0.83 & 2.27 & 0.91 & 1.88 & 1.02 & 2.39 & 1.03 \\
\hline Planning & 1.41 & 0.67 & 1.89 & 0.86 & 1.83 & 0.86 & 1.83 & 0.83 \\
\hline
\end{tabular}

Note: For Time 1, $N=304$, for Time $2, N=145$. 


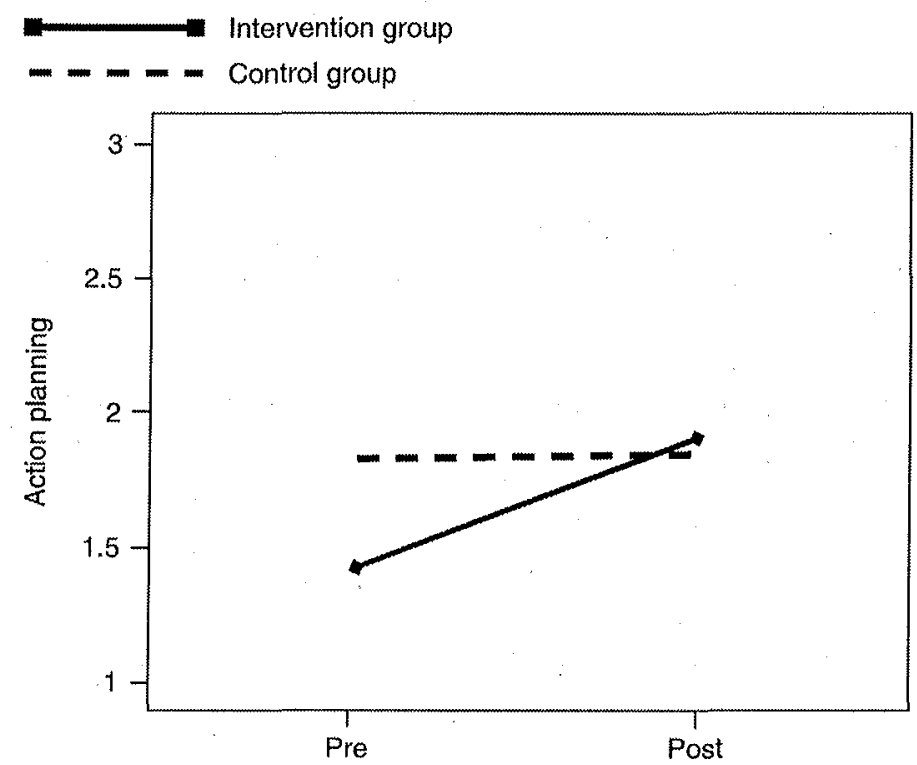

FIGURE 2. Changes in planning following an intervention to promote intention.

only. These results support the first hypothesis that motivation to change a behavior leads to increased planning activities.

\section{STUDY 2}

The second study aimed at testing the relation between the mediator and the dependent variable. Therefore, planning activities were experimentally manipulated, and behavior was assessed 1 month later.

\section{Method}

Participants and Procedure. Study 2 was conducted in a similar setting as Study 1, but with different participants. These participants did not yet consume five portions of fruit and vegetables; but they stated their intention to do so in the future $(N=246$, mean age $=44$ years, $S D=8.6$ years, ranging from 20 to 62 years, $84 \%$ men). They were randomly assigned to a planning intervention $(n=214)$ or to a control group $(n=32)$. Time 2 questionnaires were returned by 115 persons $(49.4 \%) 1$ month after treatment. Of those, 96 were in the experimental and 19 in the control group. In terms of initial self-reported intentions, planning, and dietary behavior, the longitudinal sample did not differ significantly from dropouts. 
Intervention. The proposed mediator (i.e. planning) was experimentally induced in a self-instructed, computer-based setting. Participants received the following instruction on the screen: "Please write in the space below when, where, and how you will eat 5 portions of fruit and vegetables a day." Trained interviewers answered questions or clarified misunderstandings in a nondirective manner. Self-reported planning, intention, and behavior were assessed 4 weeks later and compared to a control group without a planning intervention.

Measures. As in Study 1, self-reported planning concerning fruit and vegetable consumption and dietary behavior were measured at baseline and 4 weeks later. Fruit and vegetable intake at baseline and follow-up was assessed with an open-ended question format by asking "Regarding the last four weeks: How many portions of fruit and vegetables did you eat on an average day?" Participants received detailed information about portion sizes. Similar single-item measures of fruit and vegetable intake have been validated sucessfully against dietary biomarkers (Steptoe, Perkins-Porras, McKay, Rink, Hilton, \& Cappuccio, 2003).

Analytical Procedure. Data were analysed using a repeated-measures ANOVA to examine mean differences between the experimental and control groups. The mediating effects of changes in planning in the relation between the experimental versus the control condition and subsequent behavior were tested using hierarchical regression analyses. All analyses were conducted with SPSS 13.0.

\section{Results}

The intervention and control groups did not differ in frequency of fruit and vegetable intake at preintervention, $F(1,240)=2.15$, ns. The second hypothesis concerned the effect of a planning intervention on dietary behavior. Means and standard deviations are depicted in Table 2. A repeated-measures ANOVA revealed a marginally significant Time $\times$ Group interaction, $F(1,112)=3.18, p=.08$ (partial eta ${ }^{2}=.04$, post-hoc observed power test 0.42 ). The results are displayed in Figure 3.

Hierarchical regression tested whether the differential effects of planning and control interventions on behavior were mediated by change in planning. Time 2 fruit and vegetable intake was regressed onto baseline behavior in the first step in order to predict behavior change. In a second step, the residualised change score of planning was entered as a predictor of behavior change. This residualised change score was obtained by regressing Time 2 planning onto Time 1 planning, $R^{2}=.09 ; \beta=.30 ; p<.001$. A highly significant $\beta$ was obtained in the intervention group, $\beta=.47, p<.001$, but not in the control group, $\beta=.16$, ns. The increase in variance explained was 
TABLE 2

Means and Standard Deviations for Variables in Study 2

\begin{tabular}{|c|c|c|c|c|c|c|c|c|}
\hline & \multicolumn{4}{|c|}{ Planning Intervention Group } & \multicolumn{4}{|c|}{ Control Group } \\
\hline & \multicolumn{2}{|c|}{ Time 1} & \multicolumn{2}{|c|}{ Time 2} & \multicolumn{2}{|c|}{ Time 1} & \multicolumn{2}{|c|}{ Time 2} \\
\hline & M & $\mathrm{SD}$ & M & SD & M & SD & M & SD \\
\hline Planning & 2.44 & 1.05 & 3.12 & 0.96 & 2.05 & 1.13 & 2.00 & 0.67 \\
\hline $\begin{array}{l}\text { Frequency of fruit and } \\
\text { vegetable intake }\end{array}$ & 3.35 & 1.86 & $3.91^{\circ}$ & 1.95 & 3.32 & 1.90 & 2.92 & 1.74 \\
\hline
\end{tabular}

Note: For Time 1, $N=246$, for Time 2, $N=115$.

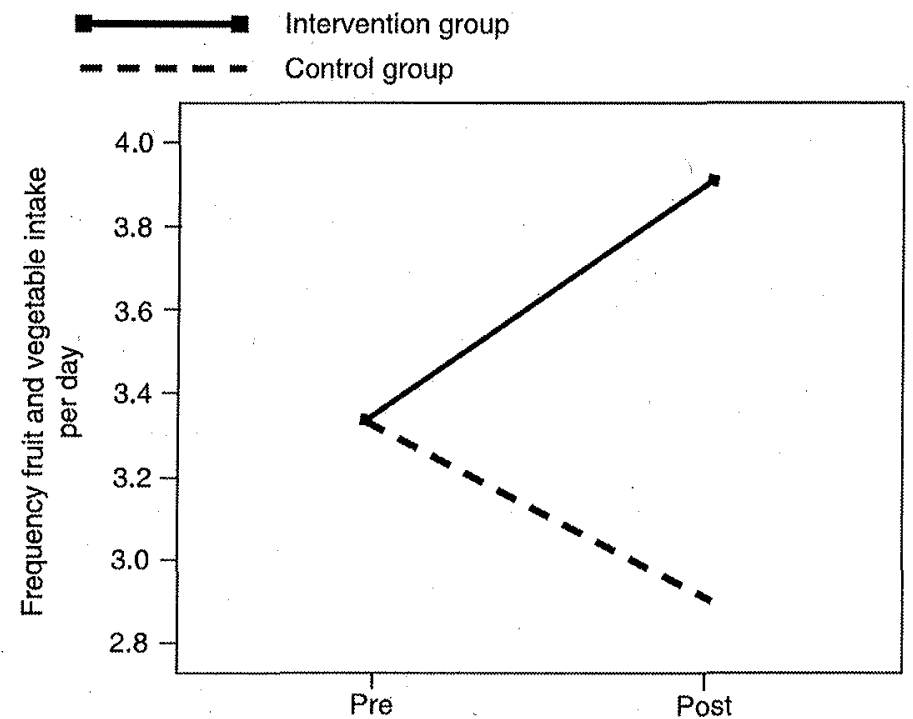

FIGURE 3. Changes in frequency of fruit and vegetable intake following a planning intervention.

significant in the intervention group only, $F(1,91)=28.50, p<.001 ; \Delta R^{2}=$ .21 ; control: $F(1,17)=0.43$, ns; $\Delta R^{2}=.02$. Hence, change in behavior can be predicted by changes in planning in the intervention group only.

\section{Discussion}

Participants of the planning treatment showed increases in behavior as opposed to participants in the control condition. Moreover, only in the 
treatment group were these changes mediated by changes in self-reported planning. These results support the second hypothesis that changes in planning enhance goal attainment. This study supports previous research on the beneficial effects of if-then planning on goal attainment (Gollwitzer \& Sheeran, 2006).

\section{GENERAL DISCUSSION}

Using an experimental-causal-chain design (Spencer et al., 2005) with two experimental studies (Study 1, Study 2), the present research investigated whether planning mediates the intention-behavior relation. Results of Study 1 demonstrated that changing intentions by a motivational intervention in formerly unmotivated persons led to an increase in self-reported planning. These changes in planning were predicted by intention changes in the treatment group only. Results of Study 2 demonstrated that individuals undergoing a planning intervention improved their behavior. Behavior change was predicted by changes in self-reported planning in the treatment group only. To summarise, an experimental causal chain from intention to behavior via planning was established. Thus, in line with Michie and Abraham (2004), it was not only demonstrated that the interventions did work and how well they worked, but also how they worked.

The present results on the basis of experimental designs corroborate the findings of observational studies (cf. Schwarzer et al., 2007). Many experimental studies use implementation intention (i.e. planning) interventions, but in those studies it is typically tested whether the effect of the intervention on behavior is mediated by increases in self-reported planning (e.g. Luszczynska, Sobczyk, \& Abraham, 2007) or by the amount of plans generated in the planning intervention (e.g. Ziegelmann, Lippke, \& Schwarzer, 2006). The studies presented here, however, provide experimental evidence for the mediation hypothesis, thereby supporting the view that intentions have an impact on behavior through planning.

The theoretical implications of these results are twofold: First, they refine the simple intention-behavior association by identifying both intentions and planning as variables that operate in a sequential manner. In addition, they cast a temporal perspective on behavior change, which commences with a motivational phase (setting a goal) and proceeds to a volitional phase (goal pursuit), ultimately leading to a specific outcome (cf. Gollwitzer, Heckhausen, \& Steller, 1990; Lewin et al., 1944).

The findings might help to identify intervention points in the process underlying health behavior change. By providing evidence for a sequence of events, or specific phases, of goal-directed behavior, the concept of tailoring interventions to stages of change is supported (cf. Lippke, Ziegelmann, \& Schwarzer, 2004; Schüz, Sniehotta, \& Schwarzer, 2007). Such a stage- 
matched approach allows for the design of parsimonious interventions (Weinstein, Rothman, \& Sutton, 1998).

The limitations of the two experimental studies are discussed below. In both studies, the attrition rate was about 50 per cent. However, at baseline, no significant differences in study variables or sociodemographic variables between participants and dropouts were found. This indicates that the longitudinal sample was representative of the initial sample.

Findings based on self-reported planning might be biased due to common error variance with self-reported behavior. However, we tried to minimise the common error variance by employing a different response format (i.e. open end) for the measure of behavior. Concerning selfreported fruit and vegetable consumption, evidence exists for the criterion validity in relation to dietary biomarkers (Steptoe et al., 2003). Regarding the measurement of planning as an outcome variable, it might prove advisable for future studies to collect the participants' planning sheets and to examine the quality or quantity of their plans. A rating scheme for the different components of planning was proposed by Ziegelmann et al. (2006).

In Study 2, we assessed the effects of a planning intervention on the initiation of goal-directed behavior 4 weeks later. The study was designed to capture the mechanisms of behavior change for this particular time frame. However, the question of long-term behavioral effects should also be studied in future experiments. In an observational study, Ziegelmann, Luszczynska, Lippke, and Schwarzer (2007) found that implementation intentions can predict physical activity over and above goal intentions for an extensive period of time (up to 12 months).

\section{Directions for Future Research}

In future research addressing volitional processes of behavior change, it would be fruitful to collect further experimental evidence for other proposed, volitional mediators of the intention-behavior relation, such as action control (e.g. Sniehotta, Scholz, \& Schwarzer, 2005; Schüz et al., 2007) or volitional self-efficacy beliefs (e.g. Renner, Spivak, Kwon, \& Schwarzer, 2007).

Furthermore, there is evidence that the proposed mediator model works better in some populations or contexts than in others. Previous research on planning has provided evidence for different mediation effects between age groups. Goal-related factors, such as intentions and planning, are more predictive of physical activity in middle-aged and older adults than in younger adults (Renner et al., 2007). Moreover, this mediator effect has been found to increase with the strength of intention (Wiedemann, Schüz, Sniehotta, Scholz, \& Schwarzer, in press). 


\section{Conclusions}

Effective goal pursuit requires self-regulation strategies, such as planning the intended behavior. Previous observational studies have demonstrated that planning mediates the intention-behavior relation (e.g. Schwarzer et al., 2007). In a further step, the two studies outlined here provide evidence for the advantages of using an experimental-causal-chain approach (Spencer et al., 2005) in order to illuminate the mediating role of planning. Hence, planning appears to be an important volitional factor for successful goal pursuit. For health-promotion interventions, it might be useful to identify a person's current phase in the behavior change process and to tailor the intervention accordingly.

\section{REFERENCES}

Ajzen, I. (1991). The theory of planned behavior. Organizational Behavior and Human Decision Processes, 50, 179-211.

Bandura, A., \& Simon, K.M. (1977). The role of proximal intentions in self-regulation of refractory behavior. Cognitive Therapy and Research, 1, 177-193.

Baron, R.M., \& Kenny, D.A. (1986). The moderator-mediator variable distinction in social psychological research: Conceptual, strategic, and statistical considerations. Journal of Personality and Social Psychology, 51, 1173-1182.

Chapman, S.L., \& Jeffrey, D.B. (1978). Situational management, standard setting, and self-reward in a behavior modification weight loss program. Journal of Consulting and Clinical Psychology, 46, 1588-1589.

Enders, C.K. (2001). A primer on maximum likelihood algorithms available for use with missing data. Structural Equation Modeling, 8, 128-141.

Fishbein, M., \& Ajzen, I. (1975). Belief, attitude, intention, and behavior: An introduction to theory and research. Reading, MA: Addison-Wesley.

Gold, M.S., \& Bentler, P.M. (2000). Treatments of missing data: A Monte Carlo comparison of RBHDI, iterative stochastic regression imputation, and expectationmaximization. Structural Equation Modeling, 7, 319-355.

Gollwitzer, P.M. (1999). Implementation intentions: Strong effects of simple plans. American Psychologist, 54, 493-503.

Gollwitzer, P.M., Heckhausen, H., \& Steller, B. (1990). Deliberative and implemental mind-sets: Cognitive tuning toward congruous thoughts and information. Journal of Personality and Social Psychology, 59, 1119-1127.

Gollwitzer, P.M., \& Sheeran, P. (2006). Implementation intentions and goal achievement: A meta-analysis of effects and processes. Advances in Experimental Social Psychology, 38, 249-268.

Greiner, J.M., \& Karoly, P. (1976). Effects of self-control training on study activity and academic performance: An analysis of self-monitoring, self-reward, and systematic planning components. Journal of Counseling Psychology, 23, 495-502.

Judd, C.M., \& Kenny, D.A. (1981). Estimating the effects of social interventions. New York: Cambridge University Press. 
Leventhal, H., Singer, R., \& Jones, S. (1965). Effects of fear and specificity of recommendation upon attitudes and behavior. Journal of Personality and Social Psychology, 2, 20-29.

Lewin, K., Dembo, T., Festinger, L.A., \& Sears, P.S. (1944). Level of aspiration. In J. McV. Hunt (Ed.), Personality and the behavior disorders (Vol. 1, pp. 333-378). New York: Ronald.

Link, B.G., \& Shrout, P.E. (1992). Spurious associations in longitudinal research. Research in Community and Mental Health, 7, 301-321.

Lippke, S., Ziegelmann, J.P., \& Schwarzer, R. (2004). Initiation and maintenance of physical exercise: Stage-specific effects of a planning intervention. Research in Sports Medicine, 12, 221-240.

Luszczynska, A., Sobczyk, A., \& Abraham, C. (2007). Planning to lose weight: Randomized controlled trial of an implementation intention prompt to enhance weight reduction among overweight and obese women. Health Psychology, 26, $507-512$.

Metcalfe, J., \& Mischel, W. (1999). A hot/cool-system analysis of delay of gratification: Dynamics of willpower. Psychological Review, 106, 3-19.

Michie, S., \& Abraham, C. (2004). Interventions to change health behaviours: Evidence-based or evidence-inspired? Psychology and Health, 19, 29-49.

Miller, G., Galanter, E., \& Pribram, K. (1960). Plans and the structure of behavior. New York: Holt, Rinehart \& Winston.

Mischel, W., \& Patterson, C.J. (1976). Substantive and structural elements of effective plans for self-control. Journal of Personality and Social Psychology, 34, 942-950.

Norman, P., \& Conner, M. (2005). The theory of planned behavior and exercise: Evidence for the mediating and moderating roles of planning on intentionbehavior relationships. Journal of Sport and Exercise Psychology, 27, 488-504.

Orbell, S., Hodgkins, S., \& Sheeran, P. (1997). Implementation intentions and the theory of planned behavior. Personality and Social Psychology Bulletin, 23, 945-954.

Rademacher, J.D.M., \& Lippke, S. (2007). Dynamic online surveys and experiments with the free open source software dynQuest. Behavior Research Methods, 39, 415-426.

Renner, B., Spivak, Y., Kwon, S., \& Schwarzer, R. (2007). Does age make a difference? Predicting physical activity of South Koreans. Psychology and Aging, 22, 482493.

Schüz, B., Sniehotta, F.F., \& Schwarzer, R. (2007). Stage-specific effects of an action control intervention on dental flossing. Health Education Research, 22, 332-341.

Schwarzer, R. (1992). Self-efficacy in the adoption and maintenance of health behaviors: Theoretical approaches and a new model. In R. Schwarzer (Ed.), Self-efficacy: Thought control of action (pp. 217-243). Washington, DC: Hemisphere.

Schwarzer, R. (2008). Modeling health behavior change: How to predict and modify the adoption and maintenance of health behaviors. Applied Psychology: An International Review, 57(1), 1-29.

Schwarzer, R., Schüz, B., Ziegelmann, J.P., Lippke, S., Luszczynska, A., \& Scholz, U. (2007). Adoption and maintenance of four health behaviors: Theory-guided longitudinal studies on dental flossing, seat belt use, dietary behavior, and physical activity. Annals of Behavioral Medicine, 33, 156-166. 
Sheeran, P. (2002). Intention-behavior relations: A conceptual and empirical review. European Review of Social Psychology, 12, 1-36.

Sniehotta, F.F., Scholz, U., \& Schwarzer, R. (2005). Bridging the intentionbehaviour gap: Planning, self-efficacy, and action control in the adoption and maintenance of physical exercise. Psychology and Health, 20, 143-160.

Spencer, S.J., Zanna, M.P., \& Fong, G.T. (2005). Establishing a causal chain: Why experiments are often more effective than mediational analyses in examining psychological processes. Journal of Personality and Social Psychology, 89, 845 851.

Steptoe, A., Perkins-Porras, L., McKay, C., Rink, E., Hilton, S., \& Cappuccio, F.P. (2003). Psychological factors associated with fruit and vegetable intake and with biomarkers in adults from a low-income neighborhood. Health Psychology, 22, $148-155$.

Verplanken, B., \& Faes, S. (1999). Good intentions, bad habits, and effects of forming implementation intentions on healthy eating. European Journal of Social Psychology, 29, 591-604.

Webb, T.L., \& Sheeran, P. (2006). Does changing behavioral intentions engender behavior change? A meta-analysis of the experimental evidence. Psychological Bulletin, 132, 249-268.

Weinstein, N.D., Rothman, A.J., \& Sutton, S.R. (1998). Stage theories of health behavior: Conceptual and methodological issues. Health Psychology, 17, 290299.

White, K.M., Terry, D.J., \& Hogg, M.A. (1994). Safer safe sex: The roles of attitudes, norms and control factors. Journal of Applied Social Psychology, 24, 2164-2192.

Wiedemann, A.U., Schüz, B., Sniehotta, F.F., Scholz, U., \& Schwarzer, R. (in press). Disentangling the relation between intentions, planning, and behaviour: $\mathrm{A}$ moderated mediation analysis. Psychology and Health.

Ziegelmann, J.P., Lippke, S., \& Schwarzer, R. (2006). Adoption and maintenance of physical activity: Planning interventions in young, middle-aged, and older adults. Psychology and Health, 21, 145-163.

Ziegelmann, J.P., Luszczynska, A., Lippke, S., \& Schwarzer, R. (2007). Are goal intentions or implementation intentions better predictors of health behavior? A longitudinal study in orthopedic rehabilitation. Rehabilitation Psychology, 52, 97-102. 